\section{P228 EFFICACY AND SAFETY OF FLUTICASONE PROPIONATE/ FORMOTEROL IN PAEDIATRIC PATIENTS WITH ASTHMA}

${ }^{1} \mathrm{~A}$ Ploszczuk, ${ }^{2} \mathrm{M}$ Bosheva, ${ }^{3} \mathrm{~K}$ Spooner, ${ }^{3} \mathrm{~T}$ Mclver, ${ }^{3} \mathrm{~S}$ Dissanayake. ${ }^{1}$ Department of Allergology and Internal Medicine, University of Bialystok, Bialystok, Poland; ${ }^{2}$ MHAT "Sveti Georgi", Plovdiv, Bulgaria; ${ }^{3}$ Mundipharma Research Ltd, Cambridge, UK

\subsection{6/thoraxjnl-2014-206260.356}

Background Fluticasone propionate (FP) and formoterol (FORM) have been combined in a single inhaler (FP/FORM; flutiform $^{\circledR}$ ) for the treatment of adolescents and adults with asthma. This study assessed the efficacy and safety of FP/FORM in paediatric asthma patients.

Methods A total of 512 patients aged 5 to $<12$ yrs were randomised 1:1:1 to 12 weeks of treatment with either FP/FORM (100/10 $\mu \mathrm{g}$ BID), FP (100 $\mu \mathrm{g}$ BID) or fluticasone propionate/salmeterol (FP/SAL) $(100 / 50 \mu \mathrm{g}$ BID) in a double-blind, parallel group, multicentre study. The objectives were to demonstrate superiority of FP/FORM to FP and non-inferiority to FP/SAL. The primary endpoint was the change from predose FEV1 at baseline to 2-hour postdose FEV1 over the 12 weeks. The two key secondary endpoints were FEV1 AUC0-4h at Week 12 and change from pre-dose FEV1 over the 12 weeks.

Results FP/FORM was superior to FP for change from predose FEV1 at baseline to 2-hour postdose FEV1 (treatment difference $=0.07 \mathrm{~L} ; 95 \% \mathrm{CI}: 0.03,0.11 ; \mathrm{p}<0.001)$ and FEV1 AUC0-4h at Week 12 (treatment difference $=0.09$ L; 95\% CI: 0.04, 0.13; $\mathrm{p}<0.001)$. FP/FORM was non-inferior to FP/SAL for change from predose FEV1 at baseline to 2-hour postdose FEV1 (treatment difference $=-0.00 \mathrm{~L} ; 95 \%$ CI: $-0.04,0.04 ; \mathrm{p}<0.001)$, AUC0-4h at Week 12 (treatment difference $=0.01 \mathrm{~L} ; 95 \% \mathrm{CI}$ : $-0.03,0.06 ; \mathrm{p}<0.001$ ) and change from predose FEV1 (treatment difference $=-0.02 \mathrm{~L} ; 95 \%$ CI: $-0.06,0.02 ; \mathrm{p}<0.001)$. The safety and tolerability profiles of all treatments were similar. Conclusion In children 5 to $<12$ yrs with asthma, FP/FORM was superior to $\mathrm{FP}$, and non-inferior to $\mathrm{FP} / \mathrm{SAL}$ for improvements in lung function, with a similar tolerability profile to both FP and FP/SAL.

Disclaimer Acknowledgement: Reproduced with permission of the European Respiratory Society: Eur Resp I September 2014; 44, Suppl. 58: In Press
P229 ONCE-DAILY TIOTROPIUM RESPIMAT® AS ADD-ON TO AT LEAST MEDIUM- TO HIGH-DOSE ICS, WITH OR WITHOUT LABA, IMPROVES LUNG FUNCTION IN PATIENTS WITH SYMPTOMATIC ASTHMA, INDEPENDENT OF ALLERGIC STATUS

${ }^{1} \mathrm{R}$ Dahl, ${ }^{2} \mathrm{~T}$ Casale, ${ }^{3} \mathrm{E}$ Pizzichini, ${ }^{4} \mathrm{M}$ Vandewalker, ${ }^{5} \mathrm{~J} \mathrm{C}$ Virchow, ${ }^{6} \mathrm{M}$ Engel, ${ }^{6} \mathrm{R}$ Sigmund, ${ }^{6} \mathrm{P}$ Moroni-Zentgraf, ${ }^{7}$ HAM Kerstjens. ${ }^{7}$ Odense University Hospital, Allergy Centre, Odense, Denmark; ${ }^{2}$ University of South Florida, Morsani College of Medicine, Tampa, USA; ${ }^{3}$ NUPAIVA (Asthma Research Centre), Universidade Federal de Santa Catarina, Florianópolis, Santa Catarina, Brazil; ${ }^{4}$ Clinical Research of the Ozarks, Colombia, USA; ${ }^{5}$ Intensive Care Medicine, Zentrum Für Innere Medizin, Klinik I, University Clinic Rostock, Rostock, Germany; ${ }^{6}$ Boehringer Ingelheim Pharma GmbH and Co. KG, Ingelheim Am Rhein, Germany; ' University Medical Center Groningen, University of Groningen, Groningen, Groningen, The Netherlands

\subsection{6/thoraxjnl-2014-206260.357}

Background A substantial number of patients have symptomatic asthma despite treatment according to guidelines. Several studies have confirmed that tiotropium Respimat ${ }^{\circledR}$, a once-daily longacting anticholinergic bronchodilator, improves lung function in symptomatic patients receiving at least medium-dose inhaled corticosteroids (ICS) + long-acting $\beta_{2}$-agonist (LABA) (Kerstjens et al. NEJM 2012;367:1198-207; Bateman et al. JACI 2011;128:315-22). Here we examine whether the atopic and/or allergic status of patients in these trials influenced their response to tiotropium Respimat ${ }^{\circledR}$.

Method Two 48-week trials of tiotropium Respimat ${ }^{\circledR} 5 \mu \mathrm{g}$ (PrimoTinA-asthma ${ }^{\circledR}:$ NCT00776984, NCT00772538) in patients ( $\mathrm{n}=912$ ) on high-dose ICS + LABA; two 24-week trials of tiotropium Respimat ${ }^{\circledR} 5 \mu \mathrm{g}$ and $2.5 \mu \mathrm{g}$ (MezzoTinA-asthma ${ }^{\circledR}$ : NCT01172808, NCT01172821) in patients $(\mathrm{n}=2100)$ on moderate-dose ICS. Pre-planned analyses (pooled populations) were performed in two subgroups defined at baseline as total serum immunoglobulin $\mathrm{E}(\mathrm{IgE}) \leq$ or $>430 \mu \mathrm{g} / \mathrm{L}$ or blood eosinophils $\leq$ or $>0.6 \times 10^{9} / \mathrm{L}$ or clinical judgement of allergic status ('No' or 'Yes'). All tiotropium doses were delivered via the Respimat ${ }^{\circledR}$ SoftMist ${ }^{\mathrm{TM}}$ inhaler.

Results Tiotropium Respimat ${ }^{\circledR} 5 \mu \mathrm{g}$ or $2.5 \mu \mathrm{g}$ improved peak and trough forced expiratory volume in 1 second versus placebo (Table) independent of IgE, eosinophil count and clinical judgement.

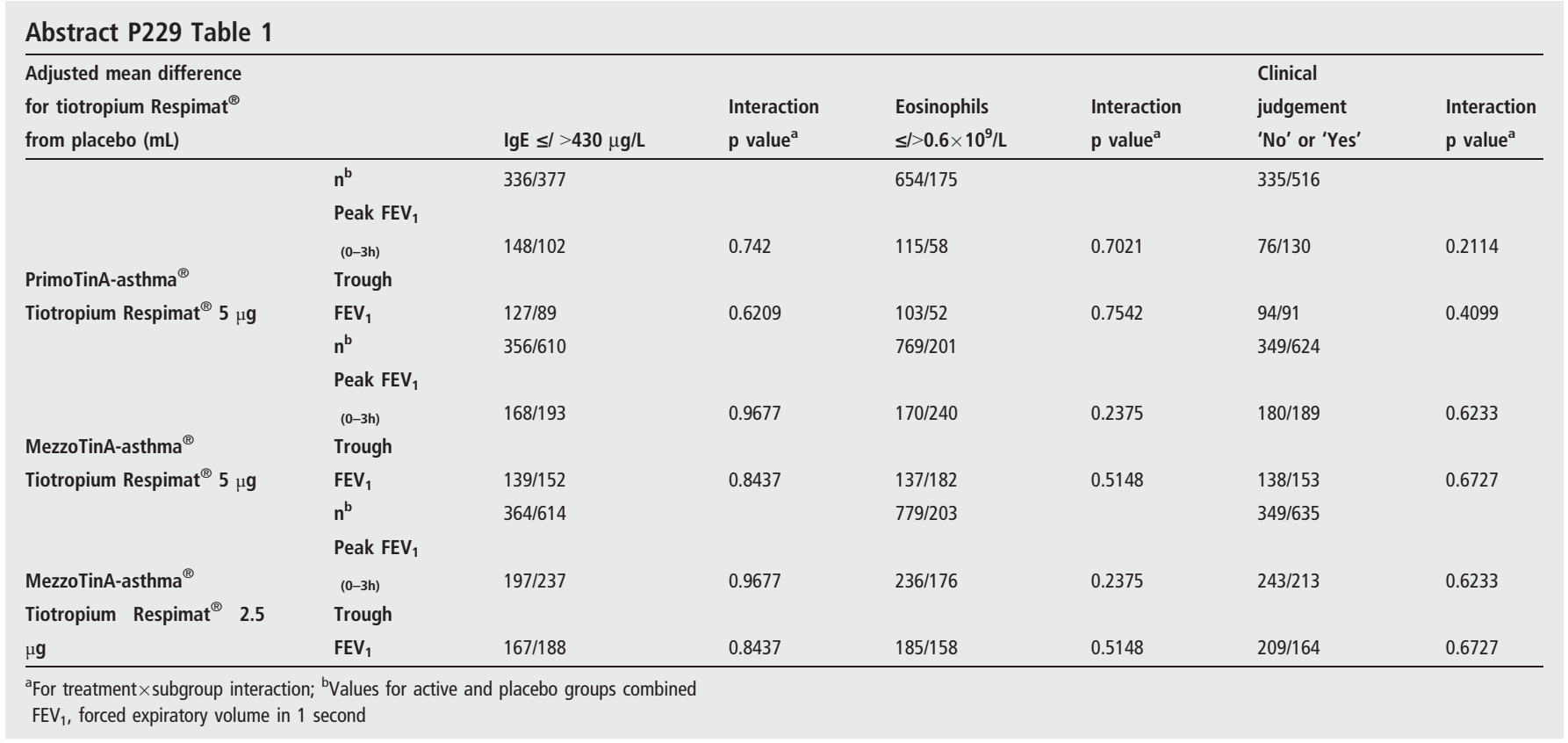


Conclusion Once-daily tiotropium Respimat ${ }^{\circledR}$ as add-on to ICS or ICS + LABA in patients with moderate to severe symptomatic asthma reduces airflow obstruction, apparently independent of their atopic and/or allergic status.

\section{P230 ONCE-DAILY TIOTROPIUM RESPIMAT® IMPROVES LUNG FUNCTION IN PATIENTS WITH SEVERE SYMPTOMATIC ASTHMA INDEPENDENT OF LEUKOTRIENE MODIFIER USE}

${ }^{1} R$ Dahl, ${ }^{2} D E$ Doherty, ${ }^{3}$ J Corren, ${ }^{4}$ J Karpel, ${ }^{5}$ HAM Kerstjens, ${ }^{6} \mathrm{M}$ Engel, ${ }^{6} \mathrm{P}$ Moroni-Zentgraf, ${ }^{6} \mathrm{H}$ Schmidt, ${ }^{7} \mathrm{~S}$ Hashimoto. ${ }^{1}$ Odense University Hospital, Allergy Centre, Odense, Denmark; 'Lexington VA Medical Center, University of Kentucky, Lexington, USA; ${ }^{3}$ University of California, California, USA; ${ }^{4}$ North Shore Medical Arts LLP, Pulmonary Medicine, Great Neck, USA; ${ }^{5}$ University Medical Center Groningen, Groningen, The Netherlands; ${ }^{6}$ Boehringer Ingelheim Pharma GmbH and Co. KG, Biberach an Der Riss, Germany; ${ }^{7}$ Nihon University School of Medicine, Tokyo, Japan

\subsection{6/thoraxjnl-2014-206260.358}

Background Once-daily tiotropium Respimat $^{\circledR}$, a long-acting anticholinergic bronchodilator, has been shown in a Phase III programme to improve lung function and reduce severe exacerbation risk in patients with severe asthma who remain symptomatic despite using inhaled corticosteroids (ICS) + long-acting $\beta_{2}$-agonist (LABA). Use of pre-trial leukotriene receptor antagonists (LTRAs) was not restricted; we analysed whether prescreening LTRA use affected tiotropium Respimat ${ }^{\circledR}$ efficacy.

Methods In two Phase III, replicate, randomised, double-blind, placebo-controlled, parallel-group trials (PrimoTinA-asthma ${ }^{\circledR}$ : NCT00772538, NCT00776984), symptomatic patients received high-dose ICS + LABA and once-daily tiotropium $5 \mu \mathrm{g}$ or placebo (both delivered via the Respimat $^{\circledR}$ SoftMist $^{\mathrm{TM}}$ inhaler). LTRAs were permitted during run-in and treatment. Co-primary end points were peak and trough forced expiratory volume in 1 second $\left(\mathrm{FEV}_{1}\right)$ responses (difference from baseline) at 24 weeks. Subgroups were defined by pre-screening LTRA use: 'Yes'/'No'. Results Of 912 randomised patients, 205 reported pre-screening LTRA use, 200 reported LTRA use during the treatment period and 187 had efficacy data at Week 24. Baseline characteristics were comparable between groups. Mean body mass index in LTRA 'Yes'/'No' groups was $27.8 \mathrm{~kg} / \mathrm{m}^{2}$ and $28.3 \mathrm{~kg} / \mathrm{m}^{2}$, respectively. Mean\% predicted $\mathrm{FEV}_{1}$ at baseline was $56 \%$ in both groups. Lung function responses improved independent of LTRA use: peak $\mathrm{FEV}_{1}$ was $99 \pm 50 \mathrm{~mL}(\mathrm{p}=0.049)$ in the LTRA 'Yes' group and $113 \pm 28 \mathrm{~mL}(\mathrm{p}<0.001)$ in the LTRA 'No' group (peak $\mathrm{FEV}_{1}$ improvements independent of concomitant LTRA use [interaction $\mathrm{p}$ value $=0.6742]$ ). Trough $\mathrm{FEV}_{1}$ (difference from placebo) was $90 \pm 46 \mathrm{~mL}(\mathrm{p}=0.052)$ in the LTRA 'Yes' group and $93 \pm 25 \mathrm{~mL}(\mathrm{p}<0.001)$ in the LTRA 'No' group (trough $\mathrm{FEV}_{1}$ improvements independent of concomitant LTRA use [interaction $\mathrm{p}$ value $=0.5218]$ ).

Conclusion Once-daily tiotropium Respimat ${ }^{\circledR}$ added to ICS + LABA improves lung function in patients with severe symptomatic asthma, independent of initial LTRA use.

\section{P231 ONCE-DAILY TIOTROPIUM RESPIMAT®: SAFETY AND TOLERABILITY RESULTS FROM FIVE PHASE III TRIALS IN ADULTS WITH SYMPTOMATIC ASTHMA}

${ }^{1} \mathrm{~J}$ Haughney, ${ }^{2} \mathrm{M}$ Vandewalker, ${ }^{3} \mathrm{E}$ Meltzer, ${ }^{4} \mathrm{P}$ Paggiaro, ${ }^{5} \mathrm{M}$ Engel, ${ }^{6} \mathrm{~A}$ Unseld, ${ }^{5} \mathrm{P}$ MoroniZentgraf, HAM Kerstiens. 'Institute of Applied Health Sciences, University of Aberdeen, Aberdeen, UK; ${ }^{2}$ Clinical Research of the Ozarks, Columbia, MO, USA; ${ }^{3}$ Allergy and Asthma Medical Group and Research Center, San Diego, USA; ${ }^{4}$ Cardiothoracic and Respiratory Pathophysiology Department, University of Pisa, Pisa, Italy; ${ }^{5}$ Boehringer Ingelheim Pharma GmbH and Co. KG, Ingelheim, Germany; ${ }^{6}$ Boehringer Ingelheim Pharma GmbH and Co., Biberach an Der Riss, Germany; 'University Medical Center Groningen, University of Groningen, Groningen, The Netherlands

\subsection{6/thoraxjnl-2014-206260.359}

Background Tiotropium Respimat ${ }^{\circledR}$, a once-daily long-acting anticholinergic agent, is effective as add-on to inhaled corticosteroids (ICS) \pm a long-acting $\beta 2$-agonist (LABA) in adults with symptomatic asthma. Safety and tolerability are key issues in the development of new therapies or established therapies in new disease areas. We present key safety data from five Phase III, randomised, double-blind, parallel-group trials that evaluated the efficacy and safety of once-daily tiotropium Respimat ${ }^{\circledR}$ versus placebo in adults with symptomatic asthma. Methods: Two 48week trials of tiotropium Respimat ${ }^{\circledR} 5 \mu \mathrm{g}$ (PrimoTinA-asthma ${ }^{\circledR}$ : NCT00776984, NCT00772538) in patients on high-dose ICS ( $\geq 800 \mu \mathrm{g}$ budesonide or equivalent) + LABA; two 24-week trials of tiotropium Respimat ${ }^{\circledR} 5 \mu \mathrm{g}$ and $2.5 \mu \mathrm{g}$ (MezzoTinAasthma ${ }^{\circledR}$ : NCT01172808, NCT01172821) in patients on moderate-dose ICS (400-800 $\mu \mathrm{g}$ budesonide or equivalent); one 12week trial of tiotropium Respimat ${ }^{\circledR} 5 \mu \mathrm{g}$ and $2.5 \mu \mathrm{g}$ (GraziaTinA-asthma ${ }^{\circledR}$ : NCT01316380) in patients on low-dose ICS (200-400 $\mu \mathrm{g}$ budesonide or equivalent). All tiotropium doses were delivered via the Respimat ${ }^{\circledR}$ SoftMist ${ }^{\mathrm{TM}}$ inhaler. Results:

\section{Abstract P231 Table 1}

\begin{tabular}{|c|c|c|c|c|c|c|c|}
\hline & & & Tiotropium Respimat $^{\circledR}$ & & & & \\
\hline & & Placebo Respimat ${ }^{\circledR}$ & $5 \mu \mathrm{g} \mathrm{QD}(\mathrm{n}=517) /$ & Salmeterol & & Tiotropium Respimat $^{\circledR}$ & Placebo Respimat ${ }^{\circledR}$ \\
\hline & Tiotropium Respimat $^{\circledR}$ & $Q D$ & $2.5 \mu \mathrm{g} Q D(n=519)$ & $50 \mu \mathrm{g} \mathrm{BID}$ & Placebo $^{\mathrm{a}}$ & $5 \mu \mathrm{g} \mathrm{QD}(\mathrm{n}=155) /$ & QD \\
\hline$\%$ & $5 \mu \mathrm{g} Q \mathrm{D}(\mathrm{n}=456)$ & $(n=456)$ & & $(n=541)$ & $(n=523)$ & $2.5 \mu \mathrm{g} Q \mathrm{D}(\mathrm{n}=154)$ & $(n=155)$ \\
\hline Any $\mathrm{AE}$ & 73.5 & 80.3 & $57.3 / 58.2$ & 54.3 & 59.1 & $32.3 / 31.2$ & 29.0 \\
\hline Drug-related $\mathrm{AE}$ & 5.7 & 4.6 & $7.4 / 6.9$ & 5.2 & 5.4 & $1.3 / 1.3$ & 1.3 \\
\hline Serious $A E$ & 8.1 & 8.8 & $2.1 / 2.3$ & 2.0 & 2.7 & $0.6 / 0$ & 0.6 \\
\hline Asthma & 39.9 & 50.9 & $21.5 / 15.8$ & 19.4 & 22.0 & $11.0 / 15.6$ & 12.9 \\
\hline Bronchitis & 5.5 & 4.4 & $2.1 / 1.7$ & 1.7 & 1.0 & $1.9 / 0$ & 0.6 \\
\hline Decreased peak expiratory flow rate & 20.4 & 26.8 & $11.4 / 9.4$ & 8.7 & 15.1 & $3.9 / 5.8$ & 3.9 \\
\hline Headache & 6.4 & 7.2 & $1.5 / 3.5$ & 1.1 & 2.7 & $1.9 / 0.6$ & 0 \\
\hline Nasopharyngitis & 11.2 & 12.3 & $7.9 / 9.4$ & 7.6 & 9.2 & $0.6 / 1.3$ & 3.2 \\
\hline Upper respiratory tract infection & 4.6 & 3.5 & $3.7 / 5.2$ & 7.6 & 7.8 & $4.5 / 1.3$ & 4.5 \\
\hline
\end{tabular}

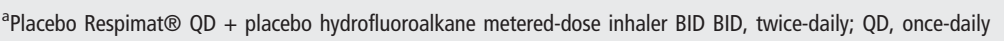

